\title{
Factors Associated with Unsuccessful Recanalization in Mechanical Thrombectomy for Acute Ischemic Stroke
}

\author{
Toshiaki Goda $^{a}$ Naoki Oyama ${ }^{a}$ Takaya Kitano ${ }^{a, b} \quad$ Takanori Iwamoto $^{a}$ \\ Shinji Yamashitaa Hiroki Takaic Shunji Matsubara ${ }^{c}$ Masaaki Uno ${ }^{c}$ \\ Yoshiki Yagita ${ }^{a}$ \\ a Department of Stroke Medicine, Kawasaki Medical School, Okayama, Japan; \\ ${ }^{b}$ Department of Neurology, Osaka University Graduate School of Medicine, Osaka, Japan; \\ 'Department of Neurosurgery, Kawasaki Medical School, Okayama, Japan
}

\section{Keywords}

Acute ischemic stroke $\cdot$ Mechanical thrombectomy $\cdot$ Unsuccessful recanalization

\begin{abstract}
Introduction: Mechanical thrombectomy (MT) for acute ischemic stroke has become a standard therapy, and the recanalization rate has significantly improved. However, some cases of unsuccessful recanalization still occur. We aimed to clarify patient factors associated with unsuccessful recanalization after MT for acute ischemic stroke. Methods: This was a single-center, retrospective study of 119 consecutive patients with anterior circulation acute ischemic stroke who underwent MT at our hospital between April 2015 and March 2019. Successful recanalization after MT was defined as modified Treatment in Cerebral Ischemia ( $\mathrm{mTICl})$ grade $2 \mathrm{~b}$ or 3, and unsuccessful recanalization was defined as $\mathrm{mTICl}$ grades $0-2 \mathrm{a}$. Several factors were analyzed to assess their effect on recanalization rates. Results: Successful recanalization was achieved in 88 patients (73.9\%). The univariate analysis showed that female sex (38.6 vs. $67.7 \%, p=0.007$ ), a history of hypertension ( $53.4 \mathrm{vs.} 83.9 \%, p=0.003$ ), and a longer time from groin puncture to recanalization (median 75 vs. $124 \mathrm{~min}, p<0.001$ ) were significantly associated with unsuccessful recanalization. The multivariate analysis confirmed that female sex (OR 3.18; $95 \% \mathrm{Cl} 1.12-9.02, p=0.030$ ), a history of hypertension (OR 4.84; $95 \% \mathrm{Cl} 1.32-17.8, p=$ 0.018 ), $\mathrm{M} 2-3$ occlusion (OR 4.26; $95 \% \mathrm{Cl} 1.36-13.3, p=0.013$ ), and the time from groin puncture to recanalization (per 10-min increase, OR 1.22; $95 \% \mathrm{Cl} 1.09-1.37, p<0.001$ ) were independently associated with unsuccessful recanalization. Conclusion: Female sex and a history of hypertension might be predictors of unsuccessful recanalization after MT for anterior circulation acute ischemic stroke. Further studies are needed to fully evaluate predictors of recanalization.




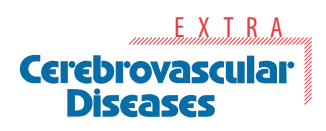

\begin{tabular}{l|l}
\hline Cerebrovasc Dis Extra 2019;9:107-113 \\
\hline DOI: 10.1159/000503001 & $\begin{array}{l}\text { (c) 2019 The Author(s). Published by S. Karger AG, Basel } \\
\text { www.karger.com/cee }\end{array}$ \\
\hline
\end{tabular}

Goda et al.: Factors Associated with Unsuccessful Recanalization in MT for Acute Ischemic Stroke

\section{Introduction}

Mechanical thrombectomy (MT) has become a standard therapy for acute ischemic stroke with large vessel occlusion [1]. Recanalization of modified Treatment in Cerebral Ischemia (mTICI) 2b or 3 is significantly associated with a good clinical outcome [2], and the recommended target angiographic end point for technical success is mTICI $2 \mathrm{~b}$ or 3 [3]. With the continued development of devices for MT, such as the stent retriever and aspiration catheter, the recanalization rate has significantly improved, reaching approximately $80 \%$ in recent trials $[1,4]$. However, unsuccessful recanalization may still occur.

In previous reports, more proximal occlusions, such as those in the internal carotid artery (ICA) and M1 segment of the middle cerebral artery (MCA), was associated with successful recanalization $[5,6]$. Other studies have revealed that an erythrocyte-rich thrombus, appearing as a hyperdense signal on computed tomography or a low-intensity signal (known as a susceptibility vessel sign) on $\mathrm{T} 2 *$ gradient echo magnetic resonance imaging, predicts successful recanalization [7-9]. Conversely, difficult anatomical access [10,11] and intracranial atherosclerotic stenosis $[9,12]$ have been reported to be associated with unsuccessful recanalization. However, patient background factors associated with successful or unsuccessful recanalization remain unknown.

Identifying background factors associated with unsuccessful recanalization is important for improving MT treatment strategies. Furthermore, if these factors are modifiable, appropriate management before the onset of stroke might increase the possibility of successful recanalization in patients with large vessel occlusion. In this study, we aimed to clarify patient factors associated with unsuccessful recanalization in MT for acute ischemic stroke.

\section{Methods}

This was a single-center, retrospective study of 119 consecutive patients with anterior circulation acute ischemic stroke who underwent MT at our hospital between April 2015 and March 2019. Successful recanalization after MT was defined as mTICI grade $2 \mathrm{~b}$ or 3 , and unsuccessful recanalization was defined as mTICI grade $0-2$ a. Several factors were analyzed to assess their effect on recanalization rates, including: sex, risk factors (history of cerebral infarction/transient ischemic attack, coronary artery disease, hypertension, diabetes mellitus, dyslipidemia, atrial fibrillation, and smoking [past and current]), antiplatelet agents and anticoagulants before the onset of stroke, BMI on admission, prestroke modified Rankin Scale, initial National Institute of Health Stroke Scale score, Alberta Stroke Program Early Computed Tomography Score for Diffusion-Weighted Imaging including deep white matter lesions [13], occluded vessels (common carotid artery, ICA, and M1-3 segment of the MCA), whether intravenous thrombolysis with a recombinant tissue plasminogen activator was performed, thrombectomy procedure, time from stroke onset to admission, time from admission to groin puncture, time from groin puncture to recanalization, and stroke subtype based on Trial of ORG 10172 in Acute Stroke Treatment criteria [14].

Hypertension was defined as the presence of a positive history or drug treatment, or persistent elevation of systolic ( $\geq 140 \mathrm{~mm} \mathrm{Hg}$ ) or diastolic blood pressure ( $\geq 90 \mathrm{~mm} \mathrm{Hg}$ ). Dyslipidemia was defined as current drug treatment, or a serum triglyceride level $\geq 150 \mathrm{mg}$ / $\mathrm{dL}$, a low-density lipoprotein cholesterol level $\geq 140 \mathrm{mg} / \mathrm{dL}$, or a high-density lipoprotein cholesterol level $\leq 40 \mathrm{mg} / \mathrm{dL}$. Diabetes mellitus was defined as the presence of a positive history or drug treatment, or fasting blood glucose $\geq 126 \mathrm{mg} / \mathrm{dL}$, or random blood glucose $\geq 200 \mathrm{mg} / \mathrm{dL}$. MT was performed using a stent retriever and/or a direct aspiration first pass 
Goda et al.: Factors Associated with Unsuccessful Recanalization in MT for Acute Ischemic Stroke

technique with the Penumbra system (Penumbra, Alameda, CA, USA) as the first choice. Devices were selected at the discretion of each operator. All clinical information was retrospectively collected from medical records.

\section{Statistical Analysis}

Differences between groups were tested using Fisher's exact test for categorical variables and the Mann-Whitney $U$ test for continuous variables. To assess the independent contribution of each variable, we performed a multiple logistic regression analysis. A backward stepwise regression model including all variables was used, and OR and 95\% CI were calculated. Variables that remained significant $(p<0.05)$ after backward selection are presented. In addition, we conducted a sensitivity analysis to assess the difference in recanalization rates between different operators (operators with or without more than 5 years of experience in neuroendovascular therapy) and thrombectomy techniques (techniques using a stent retriever only or other techniques). All analyses were conducted using EZR [15] (version 1.33; Saitama Medical Center, Jichi Medical University, Saitama, Japan), which is a graphical user interface for R (The R Foundation for Statistical Computing, Vienna, Austria). More precisely, EZR is a modified version of $\mathrm{R}$ Commander designed to add statistical functions frequently used in biostatistics.

\section{Results}

The mean age of the patients was 79 years, and 55 (46.2\%) were female and 64 (53.8\%) were male. Table 1 shows the demographic and clinical characteristics of patients with successful and unsuccessful recanalization. Successful recanalization was achieved in 88 patients (73.9\%). In the univariate analysis, female sex (38.6 vs. $67.7 \%, p=0.007$ ), a history of hypertension ( $53.4 \mathrm{vs.} 83.9 \%, p=0.003$ ), and a longer time from groin puncture to recanalization (median 75 vs. $124 \mathrm{~min}, p<0.001$ ) were significantly associated with unsuccessful recanalization. Although the difference was not significant, patients with unsuccessful recanalization tended to be younger (median 81 vs. 75 years, $p=0.17$ ) and had occlusion of more distal vessels (M2-3 segment of the MCA, 23.9 vs. 38.7\%, $p=0.16$ ), a longer time from stroke onset to admission (median 124 vs. $153 \mathrm{~min}, p=0.12$ ), and a lower frequency of cardioembolism (72.7 vs. $54.8 \%, p=0.076$ ). The multivariate analysis showed that female sex (OR 3.18; $95 \%$ CI 1.12-9.02, $p=0.030$ ), a history of hypertension (OR 4.84; 95\% CI 1.32-17.8, $p=$ 0.018 ), M2-3 occlusion (OR 4.26; 95\% CI 1.36-13.3, $p=0.013$ ), and the time from groin puncture to recanalization (per 10-min increase, OR 1.22; 95\% CI 1.09-1.37, $p<0.001$ ) were independently associated with unsuccessful recanalization (Table 2). All sensitivity analyses showed a similar association between these 4 factors and unsuccessful recanalization in each patient group (online suppl. Tables 1-4; for all online suppl. material, see www.karger.com/ doi/10.1159/000503001).

\section{Discussion}

This study's findings suggested that female sex, a history of hypertension, occlusion of distal vessels, and a longer procedure time are significant predictors of unsuccessful recanalization. Previous reports have shown that occlusion at more proximal sites in anterior circulation is associated with successful recanalization $[5,6]$, which is consistent with our results. Longer procedure times seem to be the result of technical difficulties during MT and not a cause of unsuccessful recanalization. To the best of our knowledge, this is the first study to 


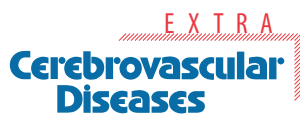

\begin{tabular}{|c|c|}
\hline \multicolumn{2}{|c|}{ Cerebrovasc Dis Extra 2019;9:107-113 } \\
\hline DOI: $10.1159 / 000503001$ & $\begin{array}{l}\text { (c) } 2019 \text { The Author(s). Published by S. Karger AG, Basel } \\
\text { www.karger.com/cee }\end{array}$ \\
\hline
\end{tabular}

Ischemic Stroke

Table 1. Demographic and clinical characteristics of the patients

\begin{tabular}{|c|c|c|c|c|}
\hline & $\begin{array}{l}\text { All } \\
(n=119)\end{array}$ & $\begin{array}{l}\text { Successful } \\
\text { recanalization } \\
(n=88)\end{array}$ & $\begin{array}{l}\text { Unsuccessful } \\
\text { recanalization } \\
(n=31)\end{array}$ & $p$ value \\
\hline Age, years & $79(70-84.5)$ & $81(71-85)$ & $75(69-84)$ & 0.17 \\
\hline Females & $55(46.2)$ & $34(38.6)$ & $21(67.7)$ & 0.007 \\
\hline \multicolumn{5}{|l|}{ Medical history } \\
\hline Ischemic stroke or TIA & $27(22.7)$ & $21(23.9)$ & $6(19.4)$ & 0.80 \\
\hline Coronary artery disease & $12(10.1)$ & $9(10.2)$ & $3(9.7)$ & $>0.99$ \\
\hline Hypertension & $73(61.3)$ & $47(53.4)$ & $26(83.9)$ & 0.003 \\
\hline Diabetes mellitus & $24(20.2)$ & 17 (19.3) & 7 (22.6) & 0.80 \\
\hline Dyslipidemia & $28(23.5)$ & $22(25.0)$ & $6(19.4)$ & 0.63 \\
\hline Atrial fibrillation & $54(45.4)$ & $41(46.6)$ & $13(41.9)$ & 0.68 \\
\hline Smoking & $46(38.7)$ & 35 (39.8) & $11(35.5)$ & 0.67 \\
\hline Antiplatelet agents & $25(21.0)$ & $20(22.7)$ & 5 (16.1) & 0.61 \\
\hline Anticoagulants & $29(24.4)$ & $20(22.7)$ & $9(29.0)$ & 0.48 \\
\hline BMI & $22.4(20.0-24.7)$ & $22.5(20.1-24.7)$ & $21.5(19.6-24.5)$ & 0.54 \\
\hline Prestroke mRS & $0(0-3)$ & $0(0-3)$ & $0(0-2)$ & 0.93 \\
\hline Systolic blood pressure, mm Hg & $159(141-171)$ & $159(140-171)$ & $160(143-168)$ & 0.97 \\
\hline Initial NIHSS & $19(14-23.5)$ & $19(14-24)$ & $19(15.5-22)$ & 0.76 \\
\hline DWI-ASPECTS & $7(5-8)$ & $7(5-9)$ & $6(5.3-7.8)$ & 0.48 \\
\hline \multicolumn{5}{|l|}{ Occluded vessel } \\
\hline CCA, ICA, or M1 & $86(72.3)$ & $67(76.1)$ & $19(61.3)$ & 0.16 \\
\hline M2-3 & $33(27.7)$ & $21(23.9)$ & $12(38.7)$ & 0.16 \\
\hline Treatment with intravenous alteplase & $46(38.7)$ & $34(38.6)$ & $12(38.7)$ & $>0.99$ \\
\hline \multicolumn{5}{|l|}{ Thrombectomy procedure } \\
\hline Stent retriever only & $61(51.3)$ & $43(48.9)$ & $18(58.1)$ & 0.41 \\
\hline Aspiration only & $35(29.4)$ & $28(31.8)$ & 7 (22.6) & 0.37 \\
\hline Both & $21(17.6)$ & $15(17.0)$ & $6(19.4)$ & 0.79 \\
\hline Time from onset to admission, min & $130(72-239)$ & $124(66-222)$ & $153(86-271)$ & 0.12 \\
\hline Time from admission to puncture, min & $73(60-97)$ & $73(60-94)$ & $68(61-110)$ & 0.84 \\
\hline Time from puncture to recanalization, min & $88(57-133)$ & $75(50-108)$ & $124(103-159)$ & $<0.001$ \\
\hline \multicolumn{5}{|l|}{ Stroke subtype } \\
\hline Cardioembolism & $81(68.1)$ & $64(72.7)$ & $17(54.8)$ & 0.076 \\
\hline Large-artery atherosclerosis & $13(10.9)$ & $9(10.2)$ & 4 (12.9) & 0.74 \\
\hline Other determined etiology & $5(4.2)$ & $3(3.4)$ & $2(6.4)$ & 0.60 \\
\hline Undetermined etiology & $20(16.8)$ & $12(13.6)$ & $8(25.8)$ & 0.16 \\
\hline
\end{tabular}

Data are presented as medians (IQR) or numbers (\%). Differences between the groups were tested using Fisher's exact tests for categorical variables and the Mann-Whitney U test for continuous variables. Successful recanalization indicates mTICI 2b or 3. Unsuccessful recanalization indicates mTICI 0-2a. TIA, transient ischemic attack; mRS, modified Rankin scale; NIHSS, National Institute of Health Stroke Scale; DWI-ASPECTS, Alberta Stroke Program Early Computed Tomography Score for DiffusionWeighted Imaging; CCA, common carotid artery; M1, M1 segment of the MCA; M2-3, M2 or M3 segment of the MCA.

Table 2. Backward stepwise multivariate logistic regression analysis for predictors of unsuccessful recanalization

\begin{tabular}{lcc}
\hline & OR (95\% CI) & $p$ value \\
\hline Female & $3.18(1.12-9.02)$ & 0.030 \\
Hypertension & $4.84(1.32-17.8)$ & 0.018 \\
M2-3 occlusion & $4.26(1.36-13.3)$ & 0.013 \\
Puncture to recanalization per 10-min increase & $1.22(1.09-1.37)$ & $<0.001$ \\
\hline
\end{tabular}

M2-3, M2 or M3 segment of the MCA. 
Goda et al.: Factors Associated with Unsuccessful Recanalization in MT for Acute Ischemic Stroke

demonstrate the significance of sex differences and hypertension as predictors of unsuccessful recanalization.

Hypertension has been reported to be associated with a high prevalence of elongated and tortuous vessels $[10,16]$, which often make navigating the catheter to the target vessel difficult. We speculate that this is how hypertension is related to unsuccessful recanalization. Another possible explanation is that hypertension is strongly associated with arterial stiffness [17]. A previous study reported that increased arterial stiffness was associated with a poor collateral flow in large vessel occlusion [18], and pretreatment poor collateral flow was a predictor of unsuccessful recanalization during endovascular therapy for acute ischemic stroke [19]. There are few previous reports showing the relationship between hypertension and unsuccessful recanalization. Ribo et al. [10] reported that hypertension was significantly associated with difficult carotid access. Baek et al. [12] reported that hypertension was significantly associated with MT failure. Why hypertension was found to be related to unsuccessful recanalization in these 2 studies and not in other studies is not known. We speculate that it might be attributable to the age of the patient populations; the mean age in the 2 studies was relatively high at over 70 years, and our cohort was significantly older at a mean age of 79 years. Hypertension might be more strongly associated with elongated/tortuous vessels and arterial stiffness in older patients because they would have had hypertension for a longer period of time, and thus vessel wall damage caused by hypertension would be more critical.

As for differences according to patients' sex, previous studies had revealed that women with ischemic stroke have worse functional outcomes than men [20], although no compelling explanations have yet been published. The Highly Effective Reperfusion Evaluated in Multiple Endovascular Stroke study, i.e., a meta-analysis of the first 5 positive randomized controlled trials of MT, showed no differences in treatment effect between women and men [1]. However, whether the treatment effect would differ in nonclinical trial populations remains unknown. One study showed that, among patients undergoing MT for acute ischemic stroke, women had worse functional outcomes at 90 days, but there was no difference in recanalization rate [21]. Another study showed that female sex was independently associated with unsuccessful recanalization, but the underlying reason was not discussed [9].

Why the recanalization rates were low among the women in our study is unknown. One possible explanation is the smaller vessel diameter. The mean diameters of the ICA and the MCA are significantly larger in men than in women [22]. The relationship between arterial diameter and procedural success or failure has been previously studied in extracranial vascular disease. Hong et al. [23] reported that smaller diameters of the external iliac artery and the target lesion artery were independent predictors of procedural failure or vesselspecific complications in endovascular treatment of iliac artery disease. It is possible that a smaller vessel diameter is also related to procedural failure during intracranial endovascular therapy. Another explanation is that there may be sex-based differences in coagulation and fibrinolysis. A previous study reported significantly higher levels of plasminogen activator inhibitor-1 in women with acute stroke compared to men [24]. High plasminogen activator inhibitor-1 levels increase coagulation activities and reduce tPA-mediated plasmin production [25], which may lead to a reduced recanalization rate in women during MT, particularly when intravenous thrombolysis is performed.

This study has several limitations. First, this was a retrospective, single-center study with a small number of patients. Further prospective multicenter studies are needed to confirm our preliminary results. Second, pathological findings in the thrombus were not examined. Pathological characteristics might be associated with the recanalization rate. For example, an erythrocyte-rich thrombus was reported to be soft and deformable, which might make thrombectomy easier [9]. To further investigate predictors of recanalization, future studies should include a pathological examination. 
In conclusion, this study showed that female sex and a history of hypertension might be associated with unsuccessful recanalization in MT for anterior circulation acute ischemic stroke. Further prospective studies are needed to fully evaluate predictors of recanalization, which may help to develop improved thrombectomy strategies.

\section{Acknowledgement}

None.

\section{Statement of Ethics}

The study protocol complied with the Declaration of Helsinki and was approved by the Ethics Committee of the Kawasaki Medical School Hospital. The procedures complied with institutional guidelines. Given the retrospective enrollment, patient consent for participation was waived.

\section{Disclosure Statement}

The authors have no conflict of interests to declare.

\section{Funding Sources}

None.

\section{Author Contributions}

Toshiaki Goda designed this study and wrote the initial draft of this paper. Takaya Kitano, Shunji Matsubara, and Yoshiki Yagita contributed to the analysis and interpretation of data and assisted in the preparation of this paper. All other authors contributed to data collection and interpretation and critically reviewed this paper. All of the authors approved the final version of this paper and agree to be accountable for all aspects of this work in ensuring that questions related to the accuracy and integrity of any part of this work are appropriately investigated and resolved.

\section{References}

1 Goyal M, Menon BK, van Zwam WH, Dippel DW, Mitchell PJ, Demchuk AM, et al.; HERMES collaborators. Endovascular thrombectomy after large-vessel ischaemic stroke: a meta-analysis of individual patient data from five randomised trials. Lancet. 2016 Apr;387(10029):1723-31.

2 Todo K, Sakai N, Imamura H, Yamagami H, Adachi H, Kono T, et al.; KCGH-CSC Registry Investigators. Successful Reperfusion with Endovascular Therapy Has Beneficial Effects on Long-Term Outcome Beyond 90 Days. Cerebrovasc Dis. 2019;47(3-4):127-34.

3 Zaidat 00, Yoo AJ, Khatri P, Tomsick TA, von Kummer R, Saver JL, et al.; Cerebral Angiographic Revascularization Grading (CARG) Collaborators; STIR Revascularization working group; STIR Thrombolysis in Cerebral Infarction (TICI) Task Force. Recommendations on angiographic revascularization grading standards for acute ischemic stroke: a consensus statement. Stroke. 2013 Sep;44(9):2650-63. 
4 Lapergue B, Blanc R, Gory B, Labreuche J, Duhamel A, Marnat G, et al.; ASTER Trial Investigators. Effect of Endovascular Contact Aspiration vs Stent Retriever on Revascularization in Patients With Acute Ischemic Stroke and Large Vessel Occlusion: The ASTER Randomized Clinical Trial. JAMA. 2017 Aug;318(5):443-52.

5 Daou B, Chalouhi N, Starke RM, Dalyai R, Hentschel K, Jabbour P, et al. Predictors of Outcome, Complications, and Recanalization of the Solitaire Device: A Study of 89 Cases. Neurosurgery. 2015 Sep;77(3):355-60.

6 Galimanis A, Jung S, Mono ML, Fischer U, Findling O, Weck A, et al. Endovascular therapy of 623 patients with anterior circulation stroke. Stroke. 2012 Apr;43(4):1052-7.

7 Shin JW, Jeong HS, Kwon HJ, Song KS, Kim J. High red blood cell composition in clots is associated with successful recanalization during intra-arterial thrombectomy. PLoS One. 2018 May;13(5):e0197492.

8 Darcourt J, Withayasuk P, Vukasinovic I, Michelozzi C, Bellanger G, Guenego A, et al. Predictive Value of Susceptibility Vessel Sign for Arterial Recanalization and Clinical Improvement in Ischemic Stroke. Stroke. 2019 Feb; 50(2):512-5.

9 Hashimoto T, Hayakawa M, Funatsu N, Yamagami H, Satow T, Takahashi JC, et al. Histopathologic Analysis of Retrieved Thrombi Associated With Successful Reperfusion After Acute Stroke Thrombectomy. Stroke. 2016 Dec;47(12):3035-7.

10 Ribo M, Flores A, Rubiera M, Pagola J, Mendonca N, Rodriguez-Luna D, et al. Difficult catheter access to the occluded vessel during endovascular treatment of acute ischemic stroke is associated with worse clinical outcome. J Neurointerv Surg. 2013 May;5 Suppl 1:i70-3.

11 Kaesmacher J, Gralla J, Mosimann PJ, Zibold F, Heldner MR, Piechowiak E, et al. Reasons for reperfusion failures in stent-retriever-based thrombectomy: registry analysis and proposal of a classification system. AJNR Am J Neuroradiol. 2018 Oct;39(10):1848-53.

12 Baek JH, Kim BM, Yoo J, Nam HS, Kim YD, Kim DJ, et al. Predictive Value of Computed Tomography Angiography-Determined Occlusion Type in Stent Retriever Thrombectomy. Stroke. 2017 Oct;48(10):2746-52.

13 Kawano H, Hirano T, Nakajima M, Inatomi Y, Yonehara T, Uchino M. Modified ASPECTS for DWI including deep white matter lesions predicts subsequent intracranial hemorrhage. J Neurol. 2012 Oct;259(10):2045-52.

14 Adams HP Jr, Bendixen BH, Kappelle LJ, Biller J, Love BB, Gordon DL, et al. Classification of subtype of acute ischemic stroke. Definitions for use in a multicenter clinical trial. TOAST. Trial of Org 10172 in Acute Stroke Treatment. Stroke. 1993 Jan;24(1):35-41.

15 Kanda Y. Investigation of the freely available easy-to-use software 'EZR' for medical statistics. Bone Marrow Transplant. 2013 Mar;48(3):452-8.

16 Han HC. Twisted blood vessels: symptoms, etiology and biomechanical mechanisms. J Vasc Res. 2012;49(3): 185-97.

17 Niiranen TJ, Kalesan B, Hamburg NM, Benjamin EJ, Mitchell GF, Vasan RS. Relative Contributions of Arterial Stiffness and Hypertension to Cardiovascular Disease: The Framingham Heart Study. J Am Heart Assoc. 2016 Oct;5(11):e004271.

18 Acampa M, Romano DG, Lazzerini PE, Leonini S, Guideri F, Tassi R, et al. Increased Arterial Stiffness is Associated with Poor Collaterals in Acute Ischemic Stroke from Large Vessel Occlusion. Curr Neurovasc Res. 2018; 15(1):34-8.

19 Bang OY, Saver JL, Kim SJ, Kim GM, Chung CS, Ovbiagele B, et al. Collateral flow predicts response to endovascular therapy for acute ischemic stroke. Stroke. 2011 Mar;42(3):693-9.

20 Lisabeth LD, Reeves MJ, Baek J, Skolarus LE, Brown DL, Zahuranec DB, et al. Factors influencing sex differences in poststroke functional outcome. Stroke. 2015 Mar;46(3):860-3.

21 Madsen TE, DeCroce-Movson E, Hemendinger M, McTaggart RA, Yaghi S, Cutting S, et al. Sex differences in 90-day outcomes after mechanical thrombectomy for acute ischemic stroke. J Neurointerv Surg. 2019 Mar; 11(3):221-5.

22 Müller HR, Brunhölzl C, Radü EW, Buser M. Sex and side differences of cerebral arterial caliber. Neuroradiology. 1991;33(3):212-6.

23 Hong SJ, Ko YG, Shin DH, Kim JS, Kim BK, Choi D, et al. Impact of Vessel Diameter Measured by Preprocedural Computed Tomography Angiography on Immediate and Late Outcomes of Endovascular Therapy for Iliac Artery Diseases. Circ J. 2017 Apr;81(5):675-81.

24 Kain K, Catto AJ, Carter AM, Young J, Bamford J, Bavington J, et al. Decreased fibrinolytic potential in South Asian women with ischaemic cerebrovascular disease. Br J Haematol. 2001 Jul;114(1):155-61.

25 Chan SL, Bishop N, Li Z, Cipolla MJ. Inhibition of PAI (Plasminogen Activator Inhibitor)-1 Improves Brain Collateral Perfusion and Injury After Acute Ischemic Stroke in Aged Hypertensive Rats. Stroke. 2018 Aug; 49(8):1969-76. 